\title{
UNDERGRADUATE COURSES IN LINGUISTICS AT UNIVERSITIES OF GREAT BRITAIN
}

\begin{abstract}
The concept of linguistics as a branch of science has been considered. Key abilities linguists possess have been defined. The need to apply to foreign experience, in particular, British one, has been justified. Relevant information sources, namely, Benchmark Statement for Linguistics (2007), data on Education UK, the official website for international students launched by the British Council, programme specifications for linguistics at a number of British universities have been reviewed. The list of higher education institutions (65) offering undergraduate courses (424) in Linguistics has been presented. Study options for undergraduate courses in Linguistics have been described. It has been stated that curricula in linguistics provided by higher education institutions do not greatly differ from each other by the content; nevertheless they preserve their own originality. General characteristics of study years (primarily three-year curricula) have been given. Teaching and learning methods and techniques as well assessment methods generally used at British universities have been listed. Positive aspects of British experience in professional training of future linguists have been outlined. Perspectives for improving the Ukrainian curricula for professional training of future linguists have been justified.
\end{abstract}

Key words: linguist, linguistics, undergraduate courses, professional training, British experience, higher education, university, Great Britain, curricula.

\section{INTRODUCTION}

In the light of Ukrainian higher education integration into the European Higher Education Area (EHEA) appear new requirements to professional training of future specialists in various fields. Subsequently, ensuring professional education quality implies both improving teaching and learning technologies and expanding connections for efficient exchange of information and human recourses that meet main principles for higher education development in the context of the Bologna process.

Lately linguistics being a fundamental cognitive science with extremely a wide range has been acquiring the top priority since programme orientations of worldwide information space and the dramatic development of information and communication technologies (ICT) has enhanced attention to the quality of future linguists' professional training. Linguists do not only possess profound theoretical knowledge and practical skills in linguistics, but, first of all, skillfully operate with communicative strategies and techniques, explore the phenomenon of language, use the latter in developing linguistic analysis, lexicographic sources, textbooks, adjust languages to people with special needs, standardize and unify scientific technical terminology etc.

UK education is, first of all, based on "freedom to be creative, support to help students achieve their best and inspiration to develop knowledge and skills". UK universities and 
colleges are regularly reviewed to ensure high standards of academic education, teaching, accommodation, welfare support and facilities. UK higher education qualifications are recognized and respected by employers and academics worldwide (Education UK, 2015).

Moreover, British universities offer a wide range of undergraduate courses which combine various modern, innovation-based approaches to studying linguistics.

In view of the above, we consider it beneficial to study general characteristics of undergraduate courses in linguistics at universities of Great Britain, and, thus, outline positive aspects of such experience that will contribute to further improvement of national higher education and professional training of future linguists.

THE AIM OF THE STUDY

The research aims at studying general characteristics of undergraduate courses in linguistics at universities of Great Britain.

\section{THEORETICAL FRAMEWORK AND REASEARCH METHODS}

Theoretical framework of our research is based, first of all, on the Benchmark Statement for Linguistics (2007) as the nature and characteristics of undergraduate courses in linguistics have been considered there; the data of the official website for international students launched by the British Council - Education UK - since the official information on higher education in the UK and results on higher education institutions providing undergraduate courses in linguistics have been presented there. In addition, we have reviewed programme specifications for linguistics at a number of British universities to study and outline general characteristics of undergraduate courses in linguistics.

In our research we have used such methods as theoretical synthesis, theoretical analysis, generalisation and systematization.

\section{RESULTS}

According to Education UK 65 higher education institutions offer 424 undergraduate courses in linguistics (see Table 1) (Education UK, 2015).

From the table above we can conclude that such an abundance of higher education institutions providing linguistics undergraduate courses affirms: 1) potential students' interest in linguistics as a field of study and desire to pursue career in the field; 2) the need for modern specialists able to widen the scope of linguistics as a science, reveal its potential and skillfully apply the obtained knowledge to various fields for the benefit of the global society.

As regards the undergraduate qualification, most universities offer undergraduate courses leading to BA, and only certain universities (University College London - BSc Experimental Linguistics; University of Reading - BSc in Language Sciences and Psychology; University of Ulster - BSc in Language and Linguistics (with an optional specialism in Counselling Studies); University of Edinburgh - BSc (Hons) in Computational Linguistics etc.) provide BSc qualification when it is studied in certain combined honours programmes (Anderson, 2011; Mansel, 2011).

Speaking about study options courses can be full-time and part-time. The duration of a course is typically three years. Occasionally, it can be four years and include studying abroad and/or be combined with study of a foreign language (University of York - BA French and Linguistics (with a year abroad); Lancaster University - BA German Studies and Linguistics (Study Abroad) etc). It should be mentioned that undergraduate degrees in Scotland take four years of study (4th year MA (Hons) in Linguistics). "This differs from elsewhere in the UK, but is a long-established European model emulated by nations throughout the world, including the US" (The University of Edinburgh, 2015). 
Undergraduate Courses at British Universities

\begin{tabular}{|c|c|c|c|c|c|}
\hline No & Name of the institution & $\begin{array}{c}\begin{array}{c}\text { Number } \\
\text { of courses }\end{array} \\
\end{array}$ & No & Name of the institution & \begin{tabular}{|l}
$\begin{array}{c}\text { Number } \\
\text { of courses }\end{array}$ \\
\end{tabular} \\
\hline 1. & Manchester Metropolitan University & 23 & \multirow[t]{2}{*}{34.} & \multirow[t]{2}{*}{ University of Westminster } & \multirow[t]{2}{*}{7} \\
\hline 2. & University of Bedfordshire & 2 & & & \\
\hline 3. & University of Nottingham & 2 & 35. & University of Edinburgh & 16 \\
\hline 4. & Nottingham Trent University & 10 & 36. & University of Manchester & 16 \\
\hline 5. & Heriot-Watt University & 13 & 37. & London Metropolitan University & 1 \\
\hline 6. & Queen Mary, University of London & 7 & 38. & City University London & 1 \\
\hline 7. & University of East Anglia UEA & 5 & 39. & University of Cambridge & 1 \\
\hline 8. & University of Glasgow & 1 & 40. & University of Winchester & 1 \\
\hline 9. & Cardiff University & 2 & 41. & University of Reading & 2 \\
\hline 10. & Kingston University & 1 & 42. & Middlesex University & 1 \\
\hline 11. & University of Aberdeen & 15 & 43. & University of Hull & 7 \\
\hline 12. & David Game College & 1 & 44. & University of Chichester & 1 \\
\hline 13. & University of Sussex & 2 & 45. & $\begin{array}{l}\text { King's College London, University } \\
\text { of London }\end{array}$ & 1 \\
\hline 14. & University of the Arts London & 1 & 46. & University of Liverpool & 2 \\
\hline 15. & University of Leeds & 16 & 47. & Bangor University & 18 \\
\hline 16. & $\begin{array}{l}\text { Queen Margaret University, } \\
\text { Edinburgh }\end{array}$ & 1 & 48. & UCL (University College London) & 5 \\
\hline 17. & University of Essex & 9 & 49. & University of Strathclyde & 1 \\
\hline 18. & Ulster University & 3 & 50. & Queen's University Belfast & 1 \\
\hline 19. & University of Sheffield & 12 & 51. & Birmingham City University & 1 \\
\hline 20. & University of York & 13 & 52. & Birkbeck, University of London & 1 \\
\hline 21. & Leeds Beckett University & 1 & 53. & Lancaster University & 10 \\
\hline 22. & University of Northampton & 2 & 54. & University of Huddlersfield & 1 \\
\hline 23. & $\begin{array}{l}\text { Bristol, University of the West of } \\
\text { England }\end{array}$ & 1 & 55. & Aston University & 6 \\
\hline 24. & University of Brighton & 3 & 56. & University of Leicester & 4 \\
\hline 25. & Swansea University & 2 & 57. & University of St Mark \& St John & 3 \\
\hline 26. & Anglia Ruskin University & 1 & 58. & University of Sunderland & 59 \\
\hline 27. & University of Kent & 12 & 59. & University of Gloucestershire & 1 \\
\hline 28. & University of Central Lancashire & 10 & 60. & University of Oxford & 1 \\
\hline 29. & Newcastle University & 8 & 61. & SOAS, University of London & 32 \\
\hline 30. & University of Portsmouth & 1 & 62. & University of Wolverhampton & 6 \\
\hline 31. & York St John University & 2 & 63. & $\begin{array}{l}\text { International College Wales } \\
\text { Swansea (ICWS) }\end{array}$ & 1 \\
\hline 32. & University of Southampton & 16 & 64. & Cardiff Metropolitan University & 1 \\
\hline 33. & University of Warwick & 15 & 65. & University of Roehampton & 4 \\
\hline
\end{tabular}

Having reviewed programme specifications in linguistics at British universities we concluded that in general curricula in linguistics provided by higher education institutions do not greatly differ from each other by the content, nevertheless they preserve their own originality (the orientation of the very higher education institution, the influence of administrative geography etc.).

During the first year of study students usually get acquainted with the linguistic discipline and master such core areas as phonetics and phonology, morphology and syntax, 
pragmatics and semantics. They also acquire necessary knowledge on how a child learns language (language acquisition), how the human brain understands and processes a language etc. At the University of Edinburgh, apart from the mentioned above, students are to learn the regional and social variations of language in general and in the English language (The University of Edinburgh, 2015); at Bangor University - Introduction to Language: How to Be a Linguist and Linguistic Terminology (Bangor University, 2015); at the University of Essex compulsory are Foundations of Sociolinguistics and Psycholinguistics (University of Essex, 2015).

In the second year the emphasis switches to linguistic theories and subsequently students deepen their knowledge in such core areas as Syntactic Theory, Phonology and either Typology or Grammatical Semantics. At the same time the second and third years of study are focused primarily on optional modules. Thus, there are examples of typical optional modules at British universities: Linguistic Theory, Language Acquisition, Sounds of the World Languages, Structures of the World Languages, Current Issues in Bilingualism, Language and Communication, Creative Writing, Second Language Acquisition, Introduction to Discourse Analysis, Introduction to the History of English, Introduction to Typology, Grammatical Semantics, Literacy and Education, Language Origins and Evolution, Stylistics, The Language of Advertising etc.

In the third year of study students are provided with opportunities to critically evaluate linguistic theories in areas of their interest and specialisation. Core modules primarily are Cognitive Linguistics, Research Methods, Topic in Phonetic and Phonological Theory, Linguistics and Philosophy of Language, Linguistic Interfaces etc. Optional modules are Forensic Linguistics, Neurolinguistics, Language, Culture and Thought, Psycholinguistics, Pragmatics, Language and Sex, Language in the Workplace: Topics in Professional Communication etc. At Lancaster University they offer also optional Schools Volunteering Module, thus, "provide with the opportunity to work as classroom volunteers in primary or secondary schools over the course of one term" (Lancaster University, 2015). Speaking about regional peculiarities at British universities at Bangor University there are also Welshmedium modules available as options in the second and third years. Also students have the opportunity to learn Welsh Linguistics (English-medium) (Bangor University, 2011).

Students are to write a dissertation (it could be an optional module, though), usually during the second semester of the third year of study (or the forth year of study for four-year curricula) on a chosen topic in linguistics studied in depth throughout the degree. The dissertation should be dedicated to the topic appropriate to the scale of the project focused on a specific research question providing scope to explore the most sophisticated evaluative and critical issues. Thus, such activity contributes to students' ability to design and undertake a significant independent research. Dissertation supervisors provide guidance to research methods, analysis of data as well as writing skills.

According to Subject Benchmark Statement for Linguistics (2007) teaching and learning methods may be drawn from among the following: lectures; seminars; group and individual tutorials; workshops; problem sets; planning, designing and executing a piece of rigorous enquiry, such as a group or individual (research project); presentations; short exercises involving data analysis; independent learning; open and resource-based learning; use of data, recources, networking and literature for the development of analytical skills; external placements; the use of relevant computer software etc. (QAA, 2007). It should be mentioned that most universities focus, mainly, on individual learning as it is a perfect way "to express your own ideas and think for yourself" (Education UK, 2015). On the website of Education UK it is indicated that "UK degree courses develop your critical thinking, decisionmaking and creativity - skills that are valued by employers worldwide" (Education UK, 2015). 
Among assessment techniques the most common are individual and group project reports; essays; a portfolio of essays or other written work; individual and presentations; critical self- and peer-evaluation; seen and unseen, written, aural and oral examinations; short exercises involving data analysis; tasks aimed at the assessment of specific skills (e.g., information technology (IC) skills, transcription skills); cumulative problem sets involving data analysis, etc (QAA, 2007).

\section{CONCLUSIONS}

So, undegraduate courses in linguistics at British universities are aimed at developing students' intellectual potential through careful and analytical study of language with a particular emphasis on understanding and exploiting theoretical approaches to the study of language. At the same time students can adjust their interests to the curricula provided with a wide range of optional modules, thus, obtaining and improving their interdisciplinary skills. The opportunity to gain valuable experience abroad increases, first for all, students' career prospects and consequently their competitiveness. Enhancing students' motivation to independent research via preferred independent study contributes to the forming of young researchers willing to explore the scope of linguistics for the benefit of the very science and the society in general. Inspiring teaching and learning methods and techniques as well as assessment methods enrich the educational process and create an encouraging atmosphere for students. Thus, the abovementioned positive aspects of British experience in professional training of linguists should be taken into consideration while developing national curricula, in particular, in linguistics. Further detailed study of programme specifications for linguistics at British universities we consider perspective for improving future linguists' professional training at native universities.

\section{REFERENCES}

1. Anderson, S. (2011). Linguistics. Retrieved 15.11.2015 from: http://www.independent. co.uk/student/into-university/az-degrees/linguistics-556564.html.

2. Bangor University. (2011). Linguistics. Program Specification. Retrieved 15.11.2015 from : http://www.bangor.ac.uk/ar/main/KIS-docs/Final/Q100.pdf.

3. Education UK. (2015). Gain a World-Class Education. Retrieved 12.10.2015 from : http://www.educationuk.org/global/articles/gain-a-world-class-education/.

4. Education UK. (2015). Postgraduate: Linguistics. Retrieved 12.11.2015 from: http://www.educationuk.org/eduk/global/sr/course/postgraduate/linguistics/118/list.html.

5. Education UK. (2015). Undergraduate: Linguistics. Retrieved 12.11.2015 from: http ://www.educationuk.org/eduk/global/sr/course/undergraduate/linguistics/118/list.html.

6. Lancaster University. (2015). English Language and Linguistics BA Hons. Retrieved 17.11.2015 from : http://www.lancaster.ac.uk/study/undergraduate/courses/englis h-language-and-linguistics-ba-hons-qqc3/\#modules.

7. Mansel, W. (2011). Linguistic Degree Course Guide. Retrieved 25.09.2015 from : http://www.telegraph.co.uk/education/universityeducation/degree courses/8550561/ Linguistics-degree-course-guide.html.

8. QAA. (2007). Subject Benchmark Statement : Linguistics. Retrieved 1.05.2015 from: http://www.qaa.ac.uk/en/Publications/Documents/Subject-benchmark-statement-Linguistics.pdf.

9. The University of Edinburgh. (2015). Undergraduate Prospectus. Retrieved 15/06.2015 from : http://www.ed.ac.uk/polopoly_fs/1.134097!/fileManager/undergraduateprospectus-2015-entry.pdf.

10. University of Essex. (2015). BA in Linguistics. Retrieved '15.11.2015 from : https://www.essex.ac.uk/coursefinder/course_details.aspx?course=ba++q100. 